Check for updates

Cite this: J. Mater. Chem. C, 2022, 10,3944

Received 27th September 2021 Accepted 1st January 2022

DOI: $10.1039 / \mathrm{d} 1 \mathrm{tc0} 0622 \mathrm{e}$

rsc.li/materials-c

\section{Amino acid functionalised perylene bisimides for aqueous solution-deposited electron transporting interlayers in organic photovoltaic devices $\dagger$}

\author{
Joseph Cameron, (D) Dave J. Adams, (D) Peter J. Skabara (D)* and \\ Emily R. Draper (D) *
}

\begin{abstract}
Solution-processable organic solar cells have the potential to offer a low-cost renewable energy source with low energy intensive processing. However, the range of materials that are compatible for forming multilayer photovoltaic devices beyond a bulk heterojunction layer is limited due to a requirement for orthogonal processing to avoid dissolution of layers. Improving charge transport is a key challenge in the pursuit of high efficiency organic photovoltaics. Therefore, the development of solution-processable electron transport layers that are suitable for orthogonal processing is important for the feasibility of solution-processed devices. Here, we present a series of amino acid appended perylene bisimides (PBIs) which have been used as electron transporting interlayers in P3HT/PC ${ }_{61} B M$ based organic photovoltaic cells. These PBIs are easily soluble in water at high $\mathrm{pH}$, allowing for easy solution processability. Despite minimal changes in molecular structure in the series of PBIs, there are profound differences in performance of the solar cells, with the phenylalanine derivative showing the most promising performance. The absorbance, morphology and photoconductivity properties of the PBIs have a strong influence on the suitability of the material as an effective interlayer.
\end{abstract}

\section{Introduction}

The drive to develop efficient, renewable energy sources is increasingly important due to the climate crisis caused by the widespread use of carbon-based fuels. Solar cells are an attractive solution due to the abundance of solar energy and there are many different types of materials that can be used to convert solar energy to electricity. Silicon-based solar cells are currently most commonly used in practice, but these are rigid and require costly and energy intensive processing. Therefore, much of the development of new materials for photovoltaic devices has focussed on processability, with solutionprocessing offering a potential low-cost, low-energy alternative to traditional technologies. Examples of materials used for solution-processed solar cells include perovskites, ${ }^{1,2}$ organic small molecules ${ }^{3,4}$ and polymers. ${ }^{5,6}$ Organic photovoltaic (OPV) devices have the potential to produce competitive power conversion efficiencies (PCEs) $>18 \%,{ }^{7-10}$ with one recent study reporting a certified PCE of $19.5 \%$ for a tandem cell. ${ }^{11}$ These recent advances are particularly owed to the development of non-fullerene acceptors.

WestCHEM, School of Chemistry, University of Glasgow, University Avenue, Glasgow, G12 8QQ, UK. E-mail: peter.skabara@glasgow.ac.uk, emily.draper@glasgow.ac.uk

$\dagger$ Electronic supplementary information (ESI) available. See DOI: 10.1039/d1tc04622e
Much research focusses on improving the efficiency of the active layer of the solar cell device by altering the molecular structure of the donor or acceptor molecules in a bulk heterojunction. However, layers such as electron transport layers (ETLS) and interlayers play an important role in enabling efficient OPV devices. One popular ETL used is zinc oxide which is transparent, low-cost and has a high electron mobility. Zinc oxide is typically used in inverted OPVs, where the ETL is deposited on top of the indium-doped tin oxide (ITO) cathode, which can improve the air stability of the solar cells. However, to allow for ohmic contact for improved electron extraction, it can be necessary to add an interlayer between the ETL and the active layer. Examples of such materials, which are often deposited as very thin layers, include polyethylenimine (PEI), ethoxylated polyethylenimine (PEIE) or conjugated polyelectrolytes (CPES). PEI and PEIE form interfacial dipoles and this reduces the work function of the layer that is deposited on top. ${ }^{12}$ The energy levels of the CPE material can also induce a reduction in work function when deposited as a thin layer on top of $\mathrm{ZnO}$ and this can inhibit non-geminate recombination and improve electron extraction. ${ }^{13,14}$ Therefore, there is great interest in the development of new interlayer materials with high electron mobility and transparency that can be processed using environmentally friendly solvents to further development on low-cost, sustainable organic solar cells.

Perylene bisimide (PBI) based materials generally have a high electron mobility, strong absorption, and good stability 
making them attractive candidates to be used in organic solar cells. They have been applied as acceptor materials in bulk heterojunction active layers with the core structure often modified to improve device performance. For example, a 3D structure material containing four PBI units and a tetraphenylethylene core, TPE-PDI ${ }_{4}$ was constructed by Liu et al. ${ }^{15}$ as a non-fullerene acceptor with high mobility and strong absorption. Separately, Meng and co-workers showed that a bay-linked PBI modified to introduce selenium atoms could be used as an acceptor material, and cells with a PDBT-T1 donor gave a $8.4 \%$ power conversion efficiency with a high fill factor $(70.2 \%) .{ }^{16}$ The two concepts, creating a 3D structure and introducing chalcogen atoms were combined by Luo et al. to form an acceptor material which was used in solar cells that gave $8.28 \%$ efficiency and a high open-circuit voltage of $1.02 \mathrm{~V}^{17}$

Although it is important to optimise the active material, many photovoltaic devices require multiple layers to improve charge transport in the device and these also strongly influence device performance. PBIs have been shown to be effective as electron transport layers as well as acceptor components. For example, Jiang et al. also used this material as an electron transport layer in inverted perovskite solar cells. ${ }^{18}$ Additionally, PBIs can be combined with other electron transporting materials to improve charge transport. Wen and co-workers demonstrated that a tetra-hydroxy PBI could be complexed to $\mathrm{Zn}$ (II) ions and used as an electrontransporting interlayer. Devices containing a PBDB-T-2F:Y6 active layer were improved to a $15.7 \%$ PCE when this interlayer was used compared to $14.9 \%$ when $\mathrm{ZnO}$ was used. ${ }^{19}$

The use of PBIs as acceptors in OPVs and as electron transport layers in perovskite and organic solar cells highlights the importance of these materials and the potential for these to improve photovoltaic performance. However, these are often processed from organic solvents which can limit their use for orthogonal processing and can have a detrimental environmental effect. PBIs are versatile and can be modified to be processable in polar solvents by introducing phosphate ${ }^{20}$ or amine $\mathrm{a}^{21}$ groups for example. Additionally, Wang and co-workers developed a PBI with imide functionalisation with phenylfluorene groups, where the fluorenes contained quaternised alkylamine side chains. ${ }^{22}$ These could be deposited as ETLs from alcohol solutions, leading to OPVs with $10 \%$ efficiency when using a PTB7-Th/[6,6]-phenyl-C ${ }_{71^{-}}$ butyric acid methyl ester ( $\left.\mathrm{PC}_{71} \mathrm{BM}\right)$ active layer. ${ }^{22}$ Harding et al. reported a different strategy with an $\mathrm{N}$-annulated $\mathrm{PBI}$ which was deprotonated with $\mathrm{NaOH}$ in an isopropanol solution but underwent spontaneous protonation when deposited by spin-coating or slot die coating. ${ }^{23}$ The deposited layer could be used as an ETL interlayer in poly(3-hexylthiophene-2,5-diyl) (P3HT)/[6,6]-phenyl-C 61 -butyric acid methyl ester $\left(\mathrm{PC}_{61} \mathrm{BM}\right)$ OPVs resulting in $2.7 \% \mathrm{PCE}^{23}$

In this work, we present the use of 8 amino acid appended PBIs as interlayers in organic photovoltaic devices. The structures are modified at the imide position with alanine (PBI-A), phenylalanine (PBI-F), histidine (PBI-H), leucine (PBI-L), serine (PBI-S), valine (PBI-V), tryptophan (PBI-W) and tyrosine (PBI-Y) shown in Fig. 1 (note we use conventional one letter codes for each of the amino acids). These materials were chosen to be studied since, despite the similarities in molecular structure, they have previously been shown to undergo different aggregation behaviour both at the molecular scale and longer length scales. This influenced the photoconductivity of these materials which was previously studied in films ${ }^{24,25}$ and xerogel states. ${ }^{26-28}$ This should also have a strong influence on performance of these materials as electron transporting interlayers. These materials are structurally simple and can be easily synthesised cheaply at scale. Additionally, the materials are processed using aqueous solutions, demonstrating that such materials can be processed using 'green' solvents in place of hydrocarbons or halogenated solvents.

\section{Experimental}

PBIs were synthesised as previously reported. ${ }^{24,27}$ In general, 1 equivalent perylenetetracarboxylic dianhydride, 2 equivalents<smiles>[R]C(C(=O)O)N1C(=O)c2ccc3c4ccc5c6c(ccc(c7ccc(c2c37)C1=O)c64)C(=O)N([C@@H]([R])C(=O)O[Na])C5=O</smiles><smiles>[R]CCCCCCCCCc1c[nH]cn1</smiles><smiles>[R]=[V]CCO</smiles>

PBI-S

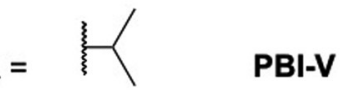<smiles>[R][R18]#N</smiles>

$R=\quad$ PBI-L<smiles>[R]=[Bi][Ba]Cc1ccc(O)cc1</smiles>

Fig. 1 Structures of PBI materials studied as electron transporting interlayers. 
of the amino acid and 40 equivalents of imidazole were added to a flask which was purged with nitrogen. The reaction mixture was heated at $120{ }^{\circ} \mathrm{C}$ for 5 hours before being cooled to $90{ }^{\circ} \mathrm{C}$. Deionised $\mathrm{H}_{2} \mathrm{O}$ was then added, and the reaction was left for a further 1 hour before being cooled to room temperature. Unreacted perylenetetracarboxylic dianhydride was then filtered off and the filtrate was acidified to a $\mathrm{pH} 2-3$ using $2 \mathrm{M}$ $\mathrm{HCl}_{(\mathrm{aq})}$ solution. This caused the amino acid appended PBI to precipitate and this was filtered before being dried in a vacuum oven overnight with a further freeze-drying step to remove any water.

PBI solutions were prepared at a concentration of $5 \mathrm{mg} \mathrm{mL} \mathrm{m}^{-1}$ by the addition of 1 equivalent of a $0.1 \mathrm{M} \mathrm{NaOH}$ solution and then made to concentration with distilled water. These solutions were then left to stir overnight to ensure dissolution of the material. Regioregular P3HT was purchased from Sigma-Aldrich (product number 445703), and $\mathrm{PC}_{61} \mathrm{BM}$ (>99.5\%) was purchased from Ossila.

Indium-doped tin oxide (ITO) covered glass slides KINTEC, $\left(7 \Omega \mathrm{sq}^{-1}, 15 \mathrm{~mm} \times 15 \mathrm{~mm} \times 1.1 \mathrm{~mm}\right)$ were cleaned by submerging in deionised water, acetone and isopropanol respectively, with ultrasonication for 5 minutes in each solvent. The substrates were then dried over a stream of compressed air before being treated with $\mathrm{O}_{2}$ plasma (Diener Electronic, Zepto model) for 10 minutes. Zinc oxide precursor solution ${ }^{29}$ was spin-coated at $2000 \mathrm{rpm}$ for 60 seconds with a ramp of 10 seconds, in ambient, at room temperature and annealed at $120{ }^{\circ} \mathrm{C}$ for 30 seconds in air. The PBI solution was then spincoated on top of the $\mathrm{ZnO}$ layer by spinning at $2000 \mathrm{rpm}$ for 60 seconds, with a ramp of 10 seconds, in the ambient, at room temperature. The substrates were then annealed at $120{ }^{\circ} \mathrm{C}$ for 20 minutes in air. A P3HT/ $\mathrm{PC}_{61} \mathrm{BM}$ solution $\left(36 \mathrm{mg} \mathrm{mL}{ }^{-1}\right.$ total concentration, $1: 0.8$ ratio, in chlorobenzene) had been stirred overnight at $40{ }^{\circ} \mathrm{C}$ in a nitrogen-filled glovebox. The active layer was deposited at $1000 \mathrm{rpm}$ for 60 seconds with a ramp of 10 seconds, in a nitrogen atmosphere at room temperature and the films were annealed at $150{ }^{\circ} \mathrm{C}$ for 20 minutes in a nitrogen atmosphere. Molybdenum trioxide $(10 \mathrm{~nm})$ was then deposited by thermal evaporation $\left(\sim 10^{-5}\right.$ mbar) before deposition of silver electrodes $(100 \mathrm{~nm})$ by thermal evaporation $\left(\sim 10^{-5}\right.$ mbar) using a shadow mask (electrode dimensions $1.5 \mathrm{~mm} \times 3.5 \mathrm{~mm})$.

Transmittance measurements were carried out using $\mathrm{ZnO} /$ PBI bilayer films deposited on ITO as described for the OPV fabrication. The spectra were recorded using a Shimadzu UV 2700 instrument.

The current-voltage characterisation of the fabricated devices was carried out using a Keithley 4200-SCS and a Newport solar simulator with a $150 \mathrm{~W}$ xenon arc lamp was used for AM1.5 illumination, which was confirmed using a calibrated solar cell. All tests were carried out in a nitrogen-filled glovebox. The $J-V$ characteristics of a minimum of 14 devices was used to calculate the average performance. External quantum efficiency measurements were carried out using a Gooch and Housego OL 750 automated spectroradiometric measurement system, with a calibrated silicon detector (OL-750-HSD-300).
Atomic force microscopy (AFM) was carried using an Innova AFM from Bruker. The surface topographies were probed using tapping mode. Film thickness was measured by slitting the films using a sharp blade to measure the height profile. The average thickness was calculated from 10 traces.

\section{Results and discussion}

There are many physical properties that can influence the performance of materials as electron transporting layers in OPVs. The amino acid functionalised PBIs self-assemble in water at high $\mathrm{pH}$ and therefore the small changes in molecular structure can result in significant changes to the absorption, electrochemical properties or photoconductivity for example, ${ }^{24}$ all of which can influence OPV performance.

The transmittance of PBI layers deposited on ITO/ZnO was studied in order to compare the effect of different side chains (Fig. 2). P3HT/ $\mathrm{PC}_{61} \mathrm{BM}$ films have a broad absorption peak between $400-700 \mathrm{~nm},{ }^{30}$ which overlaps with PBI absorption. If the PBI layer is too strongly absorbing, it could reduce the number of charge carriers formed in the active layer. PBI-L is the strongest absorbing layer by far, with a transmittance of just $15.2 \%$ at the wavelength of maximum absorbance $\left(\lambda_{\max }\right)$, due to its larger thickness with respect to the other materials (Table S1, ESI $\dagger$ ). PBI-H is the next strongest absorbing material with a transmittance of $53.8 \%$ at $509 \mathrm{~nm}$ and also forms the second thickest film from the series. PBI-A has the highest transmission at $72.3 \%$ in the visible region, whilst PBI-Y is slightly lower at $69.5 \%$. These two double layers (on $\mathrm{ZnO}$ ) are thin with measured thicknesses of 38 and $39 \mathrm{~nm}$, respectively (Table S1, ESI $\dagger$ ). The other double layers (containing PBI-F, PBI-S, PBI-V or PBI-W) have similar transmittances between 58.5-63.1\%. The absorbance range for the materials could be influenced by different types of aggregation promoted by the side chains.

It is important to ensure that the electron affinity and ionisation energy are suitably matched to avoid introducing energy barriers between layers. In inverted solar cells the interlayer will be used to facilitate charge transport from $\mathrm{PC}_{61} \mathrm{BM}$ to $\mathrm{ZnO}$. The work function of zinc oxide is $4.1 \mathrm{eV}^{29}$ and although reported values for the electron affinity range from 3.62-4.38 $\mathrm{eV}^{31}$ due to differences in reporting cyclic voltammetry data, Guan et al. reported an electron affinity for a spin-coated $\mathrm{PC}_{61} \mathrm{BM}$ film of $3.8 \mathrm{eV}$ using inverse photoemission spectroscopy. ${ }^{32}$

The previously reported electron affinities of the PBI materials studied are listed in Table S2 (ESI $\dagger) .{ }^{24}$ These energy levels lie between the $\mathrm{ZnO}$ and $\mathrm{PC}_{61} \mathrm{BM}$ or approximately level with $\mathrm{ZnO}$, which suggests the inclusion of the PBI interlayer should not create any energy barriers and can assist with charge transport in the OPV devices. The ionisation energies are also far from the reported value for regioregular P3HT of $\sim 4.5-4.7 \mathrm{eV},{ }^{33-36}$ therefore preventing transport of holes which could lead to recombination. 
(a)
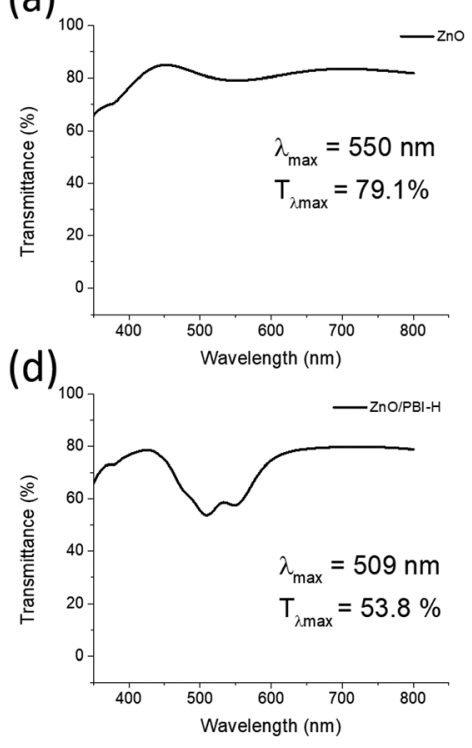

(g)

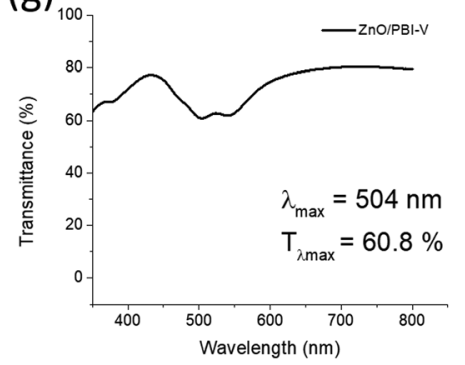

(b)

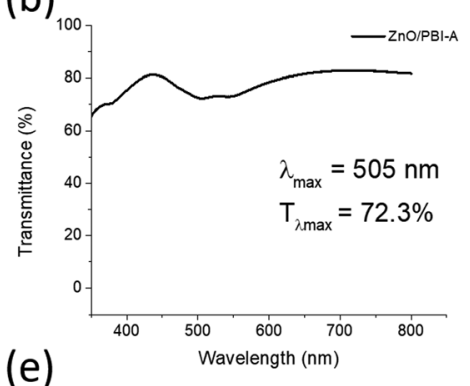

$(\mathrm{e})$

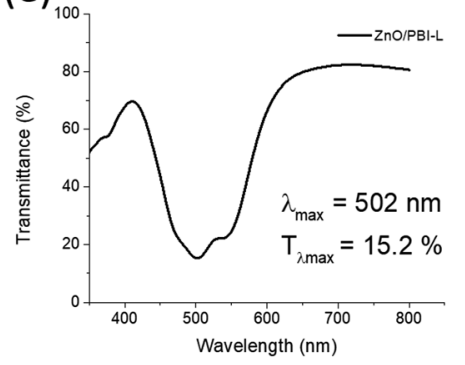

(h)

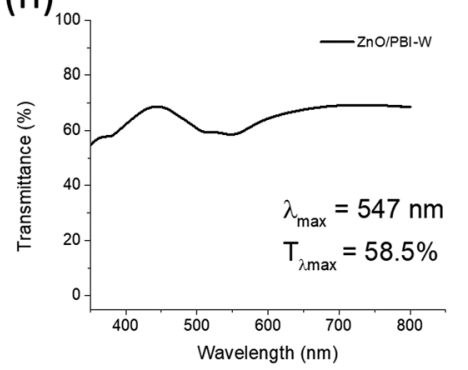

(c)

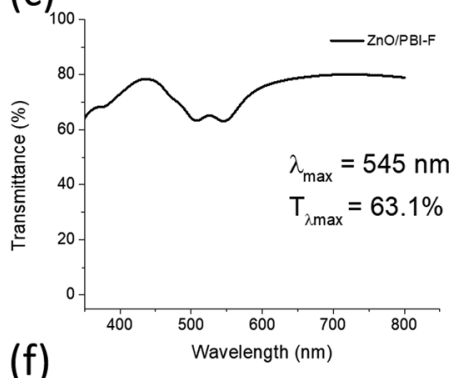

$(\mathrm{f})$

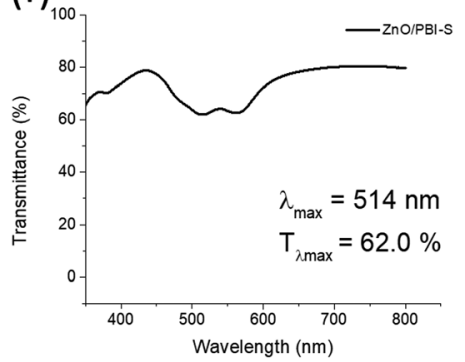

(i)

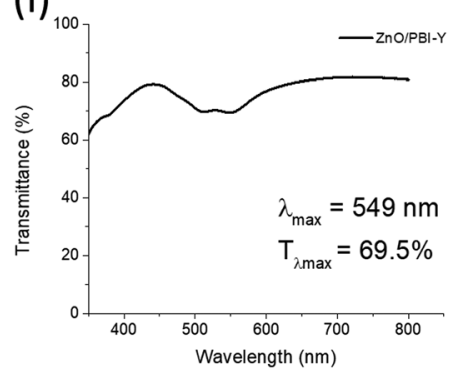

Fig. 2 Transmittance spectra of (a) ITO/ZnO and ITO/ZnO/PBI films where the PBI material used is (b) PBI-A (38 nm), (c) PBI-F (26 nm), (d) PBI-H (71 nm), (e) PBI-L (264 nm), (f) PBI-S (38 nm), (g) PBI-V (37 nm), (h) PBI-W $(66 \mathrm{~nm})$, (i) PBI-Y (39 nm). Transmittance at $\lambda_{\text {max }}$ is reported for the visible region. The average thickness measured for the $\mathrm{ZnO} / \mathrm{PBI}$ double layers are stated in parentheses.

The PBI layers were applied as interlayers between the zinc oxide electron transport layer and the $\mathrm{P} 3 \mathrm{HT} / \mathrm{PC}_{61} \mathrm{BM}$ active layer with the results summarised in Table 1 and example $J-V$ plots presented in Fig. S1 (ESI $\dagger$ ). $\mathrm{P} 3 \mathrm{HT} / \mathrm{PC}_{61} \mathrm{BM}$ based solar cells were selected for these experiments as they are well studied and therefore make suitable reference devices. The reported efficiency of inverted OPVs containing a P3HT/ $\mathrm{PC}_{61} \mathrm{BM}$ active layer can vary between $1.9-3.85 \%^{37-40}$ depending on variables such as the polymer batch and the conditions used for processing. Previous examples of $\mathrm{P} 3 \mathrm{HT} / \mathrm{PC}_{61} \mathrm{BM}$ devices with a PBI-related electron transport layer include a report by Nian and co-workers that showed a large increase in PCE to $4.48 \%$ when the PBI material (also named PBI-H, see Fig. 3) was used as a cathode interlayer by depositing from THF solutions, with the ZnO reference giving a PCE of $3.13 \% .{ }^{41}$ Also, the use of the material PDIN-H (Fig. 3), by Harding et al. showed a $2.7 \%$ PCE, compared to $2.8 \%$ for the $\mathrm{ZnO}$ control device. ${ }^{23}$ This example is comparable to the best performing amino acid appended PBIs which exhibit higher $J_{\mathrm{SC}}$ values, but lower $V_{\mathrm{OC}}$ and fill factors, which may be attributed to differences in fabrication methods and the P3HT used.

Using PBI-F as the interlayer results in an increase in the short circuit current density $\left(J_{\mathrm{SC}}\right)$ with respect to the reference
Table 1 Summary of the averaged results from P3HT/PC ${ }_{61} B M$ OPV devices

\begin{tabular}{lllll}
\hline ETL & $V_{\text {OC }}(\mathrm{V})$ & Fill factor & $J_{\mathrm{SC}}{ }^{a}\left(\mathrm{~mA} \mathrm{~cm}^{-2}\right)$ & $\mathrm{PCE}^{b}(\%)$ \\
\hline ZnO (reference) & 0.58 & 0.50 & $7.78(7.54)$ & $2.25(0.44)$ \\
ZnO/PBI-A & 0.36 & 0.45 & $6.14(6.52)$ & $1.00(0.24)$ \\
ZnO/PBI-F & 0.58 & 0.49 & $8.87(10.18)$ & $2.55(0.16)$ \\
ZnO/PBI-H & 0.53 & 0.47 & $7.06(7.67)$ & $1.96(0.33)$ \\
ZnO/PBI-L & 0.54 & 0.36 & $3.56(4.06)$ & $0.72(0.19)$ \\
ZnO/PBI-S & 0.55 & 0.50 & $7.39(7.21)$ & $2.03(0.28)$ \\
ZnO/PBI-V & 0.51 & 0.47 & $6.75(7.55)$ & $1.64(0.43)$ \\
ZnO/PBI-W & 0.61 & 0.50 & $7.38(7.30)$ & $2.24(0.26)$ \\
ZnO/PBI-Y & 0.61 & 0.48 & $7.64(6.25)$ & $2.21(0.22)$
\end{tabular}

${ }^{a} J_{\mathrm{SC}}$ calculated from the integration of EQE plots shown in parentheses. ${ }^{b}$ Standard deviation presented in parentheses.

device containing only a zinc oxide layer. This results in an average PCE of $2.55 \%$ which is higher than for the reference device $(\mathrm{PCE}=2.25 \%)$. Although adding a PBI interlayer may reduce the amount of light reaching the active layer, the electron deficient nature of PBIs can assist with charge separation of the exciton, resulting in improved short-circuit current. Layers PBI-W and PBI-Y show a slight reduction in the shortcircuit current density compared to the reference but an 


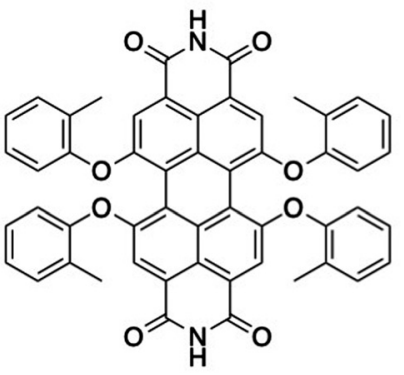

PBI-H, Nian et al. ${ }^{41}$

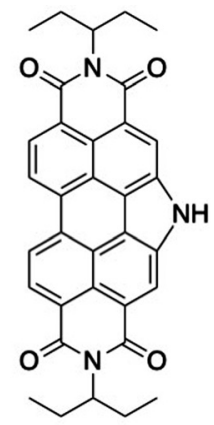

PBI-H, Harding et al..$^{23}$
Fig. 3 Structures of $\mathrm{PBI}$-based materials previously used as electron transporting interlayers in $\mathrm{P} 3 \mathrm{HT} / \mathrm{PC}_{61} \mathrm{BM}_{\mathrm{OPV}}$. $^{23,41}$

increased open-circuit voltage $\left(V_{\mathrm{OC}}\right)$ results in similar PCEs for these devices (2.24\% and $2.21 \%$, respectively).

Devices containing PBI-L exhibit the lowest $J_{\mathrm{SC}}$ and PCE and this can be explained by the parasitic absorption of the PBI-L layer, which has an approximate three-fold reduction in transmittance at the $\lambda_{\max }$ compared to the other PBI layers. Similarly, PBI-H had the second strongest absorption of the films and has a low $J_{\mathrm{SC}}$ and consequently PCE, attributed to parasitic absorption from the interlayer.

External quantum efficiency (EQE) plots for the fabricated devices are shown in Fig. S2 (ESI $\dagger$ ). The solar cell containing only a $\mathrm{ZnO}$ electron transport layer had a peak EQE of $34.9 \%$ at $547 \mathrm{~nm}$. All devices containing PBI layers showed reduced EQE at the same wavelength, highlighting the parasitic absorption from the strongly absorbing PBI layers, particularly in PBI-L. However, there is increased absorption at lower wavelengths in the best performing PBI-containing devices. This is most evident in cells containing PBI-F which has an EQE of $35.7 \%$ at $450 \mathrm{~nm}$, which is significantly larger than the $\mathrm{ZnO}$-based device with an EQE of $24.3 \%$ at the same wavelength. This suggests that there is improved absorption of the $\mathrm{P} 3 \mathrm{HT} / \mathrm{PC}_{61} \mathrm{BM}$ layer where there is no parasitic absorption from the PBI and this suggests that some of the PBI interlayers improve charge transport in the photovoltaic devices. Cells containing PBI-A, PBI-F, PBI-H, PBI-S and PBI-W have a larger EQE at $450 \mathrm{~nm}$ compared to the reference ZnO-based device. Clearly, there is a difficult balance to be struck in using PBI electron transporting interlayers where an improvement in charge transport can be counteracted by a reduction in the number of charge carriers due to absorption of the PBI layer.

Although PBI-A shows low transmittance and low electron affinity, the OPV performance when this layer is used is low, with an especially large reduction in the $V_{\mathrm{OC}}$. This can be explained by atomic force microscopy studies. Images of P3HT/ $\mathrm{PC}_{61} \mathrm{BM}$ deposited layers onto PBI-A, PBI-F and ZnO surfaces have been presented in Fig. 4. All images show common features of the long narrow $\mathrm{ZnO}$ aggregates. However, the topography image of the active layer on PBI-A shows many small domains suggesting that there is phase segregation, whilst the bulk films of the active layers deposited on PBI-F

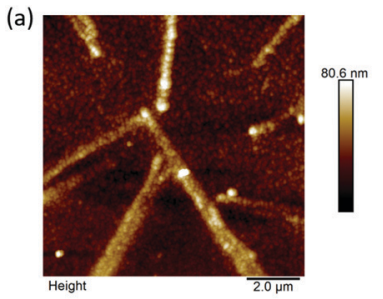

(b)
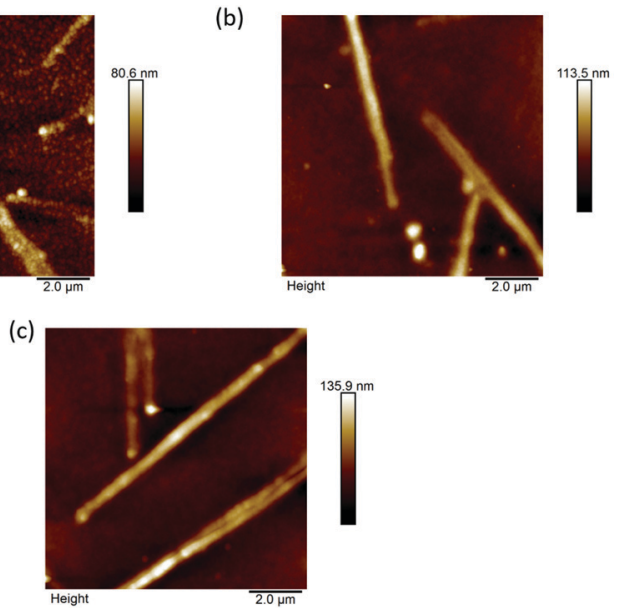

Fig. 4 AFM topography images of $\mathrm{P} 3 \mathrm{HT} / \mathrm{PC}_{61} \mathrm{BM}$ deposited on (a) ITO/ $\mathrm{ZnO} / \mathrm{PBI}-\mathrm{A}$, (b) ITO/ZnO/PBI-F and (c) ITO/ZnO.

and $\mathrm{ZnO}$ are mostly uniform. Tang and co-workers previously showed that the large donor/acceptor areas caused by phase segregation can lead to non-radiative recombination and a loss of voltage in the solar cells, ${ }^{42}$ which is consistent with the observations for PBI-A based devices.

There is a general trend where the best performing PBI layers (PBI-F, PBI-W and PBI-Y) are also those that exhibit a $\lambda_{\max }$ at $\sim 545 \mathrm{~nm}$, which is ascribed to the $\mathrm{S}_{0}-\mathrm{S}_{1}$ transition, whereas other materials show a $\lambda_{\max }$ at $\sim 505 \mathrm{~nm}$ for the $\mathrm{S}_{0}-\mathrm{S}_{2}$ transition. The absorption profile in thin film is influenced by the molecular packing. ${ }^{24}$ Therefore, we believe that improved molecular packing in PBI-F, PBI-W and PBI-Y is responsible for their improved performance compared to the other amino acid-appended PBI materials. In addition to an overall improvement in efficiency, the open-circuit voltage values are highest when these three materials are used as interlayers. The opencircuit voltage is affected by many factors including morphology, work function of electrodes and the HOMO energy of the donor and LUMO energy of the acceptor for example. ${ }^{43} \mathrm{As}$ all of these PBI materials have similar energy levels (Table S2, ESI $\uparrow$ ), it is most likely that the aggregation of the PBIs, leading to improved electron extraction, will have the largest influence on the difference in $V_{\mathrm{OC}}$ in the series of compounds. The higher $V_{\mathrm{OC}}$ values for PBI-F, PBI-W and PBI-Y provides further evidence that these aggregate more favourably for electron transport. It is noted that these materials contain the largest aromatic side groups of the PBI materials, therefore we expect that $\pi-\pi$ stacking plays an important role in inducing more favourable aggregation.

The photoconductivity of the interlayer can also have an influence on the device performance. Zhao et al. showed that an asymmetric PBI enhanced the photoconductivity when used to dope the $\mathrm{ZnO}$ layer and this contributed to increased efficiency of PTB7/PC $\mathrm{PC}_{71} \mathrm{BM}$ based OPVs. ${ }^{44}$ When the photoconductivity of the amino acid appended PBIs was studied, PBI-F, PBI-Y and PBI-W showed the lowest photoconductivity, indicating that radical anions (or dianions) were not readily formed under 
illumination. ${ }^{24}$ Notably, it is these materials that are used in the highest performing OPV devices, and indeed exhibit the highest open-circuit voltages. This suggests that formation of PBI radical anions or dianions in the interlayer upon illumination (in additions to free charge carriers formed in the bulk heterojunction after charge transfer) can lead to recombination and thus reduce the efficiency of the OPVs. The trend does not hold for the whole series, i.e., the most photoconductive material does not give the worst performance as an interlayer. However, this can be partially explained by other factors, such as the PBI-L layer showing the strongest parasitic absorption for example. This highlights the importance of molecular design for PBI materials to be used in solar cells as subtle changes to the molecular structure can have large implications for device performance.

\section{Conclusions}

A series of amino acid appended PBIs have been used as interlayers between $\mathrm{ZnO}$ and $\mathrm{P} 3 \mathrm{HT} / \mathrm{PC}_{61} \mathrm{BM}$ in inverted OPV devices with the phenylalanine (PBI-F) derivative in particular showing good shortcircuit current, whilst tryptophan (PBI-W) and tyrosine (PBI-Y) analogues improve the open-circuit voltage with only a small reduction in short-circuit current. The PBIs are deposited from basic aqueous solutions, highlighting that these materials show promising performance for solution-processed multilayer devices where orthogonal processing is necessary. Moreover, the use of aqueous solutions allows for 'greener' processing, which is an important consideration for the manufacturing of organic photovoltaics, particularly as they have the potential to be fabricated on a large scale. Further development of such materials could be promising for implementation in tandem solar cells which can be a successful strategy for enhancing the power conversion efficiency of organic photovoltaics.

\section{Conflicts of interest}

There are no conflicts to declare.

\section{Acknowledgements}

The authors thank EPSRC for funding (EP/L021978/2, EP/ P02744X/2, EP/S032673/1). E. R. D. thanks the Leverhulme Trust for funding (ECF-2017-223) and the University of Glasgow for an LKAS Leadership Fellowship. Raw data associated with the manuscript can be accessed at http://dx.doi.org/10.5525/ gla.researchdata.1186.

\section{References}

1 X. Chang, J. Fang, Y. Fan, T. Luo, H. Su, Y. Zhang, J. Lu, L. Tsetseris, T. D. Anthopoulos, S. Liu and K. Zhao, Adv. Mater., 2020, 32, 2001243.
2 D.-Y. Son, J.-W. Lee, Y. J. Choi, I.-H. Jang, S. Lee, P. J. Yoo, H. Shin, N. Ahn, M. Choi, D. Kim and N.-G. Park, Nat. Energy, 2016, 1, 16081.

3 R. Zhou, Z. Jiang, C. Yang, J. Yu, J. Feng, M. A. Adil, D. Deng, W. Zou, J. Zhang, K. Lu, W. Ma, F. Gao and Z. Wei, Nat. Commun., 2019, 10, 5393.

4 M.-A. Pan, T.-K. Lau, Y. Tang, Y.-C. Wu, T. Liu, K. Li, M.-C. Chen, X. Lu, W. Ma and C. Zhan, J. Mater. Chem. A, 2019, 7, 20713-20722.

5 X. Liu, X. Li, N. Zheng, C. Gu, L. Wang, J. Fang and C. Yang, ACS Appl. Mater. Interfaces, 2019, 11, 43433-43440.

6 Z.-G. Zhang, Y. Yang, J. Yao, L. Xue, S. Chen, X. Li, W. Morrison, C. Yang and Y. Li, Angew. Chem., Int. Ed., 2017, 56, 13503-13507.

7 Y. Cai, Y. Li, R. Wang, H. Wu, Z. Chen, J. Zhang, Z. Ma, X. Hao, Y. Zhao, C. Zhang, F. Huang and Y. Sun, Adv. Mater., 2021, 33, 2101733.

8 Y. Lin, A. Magomedov, Y. Firdaus, D. Kaltsas, A. El-Labban, H. Faber, D. R. Naphade, E. Yengel, X. Zheng, E. Yarali, N. Chaturvedi, K. Loganathan, D. Gkeka, S. H. AlShammari, O. M. Bakr, F. Laquai, L. Tsetseris, V. Getautis and T. D. Anthopoulos, ChemSusChem, 2021, 14, 3569-3578.

9 Q. Liu, Y. Jiang, K. Jin, J. Qin, J. Xu, W. Li, J. Xiong, J. Liu, Z. Xiao, K. Sun, S. Yang, X. Zhang and L. Ding, Sci. Bull., 2020, 65, 272-275.

10 Y. Cui, Y. Xu, H. Yao, P. Bi, L. Hong, J. Zhang, Y. Zu, T. Zhang, J. Qin, J. Ren, Z. Chen, C. He, X. Hao, Z. Wei and J. Hou, Adv. Mater., 2021, 33, 2102420.

11 J. Wang, Z. Zheng, Y. Zu, Y. Wang, X. Liu, S. Zhang, M. Zhang and J. Hou, Adv. Mater., 2021, 33, 2102787.

12 Y. Zhou, C. Fuentes-Hernandez, J. Shim, J. Meyer, A. J. Giordano, H. Li, P. Winget, T. Papadopoulos, H. Cheun, J. Kim, M. Fenoll, A. Dindar, W. Haske, E. Najafabadi, T. M. Khan, H. Sojoudi, S. Barlow, S. Graham, J.-L. Brédas, S. R. Marder, A. Kahn and B. Kippelen, Science, 2012, 336, 327-332.

13 J. Subbiah, V. D. Mitchell, N. K. C. Hui, D. J. Jones and W. W. H. Wong, Angew. Chem., Int. Ed., 2017, 56, 8431-8434.

14 Y.-M. Chang and C.-Y. Leu, J. Mater. Chem. A, 2013, 1, 6446-6451.

15 Y. Liu, C. Mu, K. Jiang, J. Zhao, Y. Li, L. Zhang, Z. Li, J. Y. L. Lai, H. Hu, T. Ma, R. Hu, D. Yu, X. Huang, B. Z. Tang and H. Yan, Adv. Mater., 2015, 27, 1015-1020.

16 D. Meng, D. Sun, C. Zhong, T. Liu, B. Fan, L. Huo, Y. Li, W. Jiang, H. Choi, T. Kim, J. Y. Kim, Y. Sun, Z. Wang and A. J. Heeger, J. Am. Chem. Soc., 2016, 138, 375-380.

17 Z. Luo, T. Liu, W. Cheng, K. Wu, D. Xie, L. Huo, Y. Sun and C. Yang, J. Mater. Chem. C, 2018, 6, 1136-1142.

18 K. Jiang, F. Wu, H. Yu, Y. Yao, G. Zhang, L. Zhu and H. Yan, J. Mater. Chem. A, 2018, 6, 16868-16873.

19 X. Wen, A. Nowak-Król, O. Nagler, F. Kraus, N. Zhu, N. Zheng, M. Müller, D. Schmidt, Z. Xie and F. Würthner, Angew. Chem., Int. Ed., 2019, 58, 13051-13055.

20 D. Hu, L. Yao, B. Yang and Y. Ma, Philos. Trans. R. Soc., A, 2015, 373, 20140318.

21 Z.-G. Zhang, B. Qi, Z. Jin, D. Chi, Z. Qi, Y. Li and J. Wang, Energy Environ. Sci., 2014, 7, 1966-1973. 
22 Z. Wang, N. Zheng, W. Zhang, H. Yan, Z. Xie, Y. Ma, F. Huang and Y. Cao, Adv. Energy Mater., 2017, 7, 1700232.

23 C. R. Harding, J. Cann, A. Laventure, M. Sadeghianlemraski, M. Abd-Ellah, K. R. Rao, B. S. Gelfand, H. Aziz, L. Kaake, C. Risko and G. C. Welch, Mater. Horiz., 2020, 7, 2959-2969.

24 E. R. Draper, L. J. Archibald, M. C. Nolan, R. Schweins, M. A. Zwijnenburg, S. Sproules and D. J. Adams, Chem. Eur. J., 2018, 24, 4006-4010.

25 V. Adams, J. Cameron, M. Wallace and E. R. Draper, Chem. Eur. J., 2020, 26, 9879-9882.

26 S. Roy, D. Kumar Maiti, S. Panigrahi, D. Basak and A. Banerjee, RSC Adv., 2012, 2, 11053-11060.

27 E. R. Draper, J. J. Walsh, T. O. McDonald, M. A. Zwijnenburg, P. J. Cameron, A. J. Cowan and D. J. Adams, J. Mater. Chem. C, 2014, 2, 5570-5575.

28 E. R. Draper, J. R. Lee, M. Wallace, F. Jäckel, A. J. Cowan and D. J. Adams, Chem. Sci., 2016, 7, 6499-6505.

29 S. Höfle, A. Schienle, M. Bruns, U. Lemmer and A. Colsmann, Adv. Mater., 2014, 26, 2750-2754.

30 F. Zheng, X.-Y. Yang, P.-Q. Bi, M.-S. Niu, C.-K. Lv, L. Feng, W. Qin, Y.-Z. Wang, X.-T. Hao and K. P. Ghiggino, Org. Electron., 2017, 44, 149-158.

31 B. W. Larson, J. B. Whitaker, X.-B. Wang, A. A. Popov, G. Rumbles, N. Kopidakis, S. H. Strauss and O. V. Boltalina, J. Phys. Chem. C, 2013, 117, 14958-14964.

32 Z.-L. Guan, J. B. Kim, H. Wang, C. Jaye, D. A. Fischer, Y.-L. Loo and A. Kahn, Org. Electron., 2010, 11, 1779-1785.
33 H. Aarnio, P. Sehati, S. Braun, M. Nyman, M. P. de Jong, M. Fahlman and R. Österbacka, Adv. Energy Mater., 2011, 1, 792-797.

34 N. Chandrasekaran, A. Kumar, L. Thomsen, D. Kabra and C. R. McNeill, Mater. Adv., 2021, 2, 2045-2054.

35 R. J. Davis, M. T. Lloyd, S. R. Ferreira, M. J. Bruzek, S. E. Watkins, L. Lindell, P. Sehati, M. Fahlman, J. E. Anthony and J. W. P. Hsu, J. Mater. Chem., 2011, 21, 1721-1729.

36 J.-P. Sun, J. T. Blaskovits, T. Bura, S. Beaupré, M. Leclerc and I. G. Hill, Org. Electron., 2017, 50, 115-120.

37 K. D. M. Rao, C. Hunger, R. Gupta, G. U. Kulkarni and M. Thelakkat, Phys. Chem. Chem. Phys., 2014, 16, 15107-15110.

38 N. Chander, S. Singh and S. S. K. Iyer, Sol. Energy Mater. Sol. Cells, 2017, 161, 407-415.

39 L. Yan, J. Yi, Q. Chen, J. Dou, Y. Yang, X. Liu, L. Chen and C.-Q. Ma, J. Mater. Chem. A, 2017, 5, 10010-10020.

40 L. K. Jagadamma, M. Abdelsamie, A. El Labban, E. Aresu, G. O. Ngongang Ndjawa, D. H. Anjum, D. Cha, P. M. Beaujuge and A. Amassian, J. Mater. Chem. A, 2014, 2, 13321-13331.

41 L. Nian, W. Zhang, S. Wu, L. Qin, L. Liu, Z. Xie, H. Wu and Y. Ma, ACS Appl. Mater. Interfaces, 2015, 7, 25821-25827.

42 Z. Tang, J. Wang, A. Melianas, Y. Wu, R. Kroon, W. Li, W. Ma, M. R. Andersson, Z. Ma, W. Cai, W. Tress and O. Inganäs, J. Mater. Chem. A, 2018, 6, 12574-12581.

43 N. K. Elumalai and A. Uddin, Energy Emviron. Sci., 2016, 9, 391-410. 44 H. Zhao, Y. Luo, L. Liu, Z. Xie and Y. Ma, Mater. Chem. Front., 2017, 1, 1087-1092. 